Fecha de recepción: 09-10-2017

Fecha de aceptación: 19-01-2018

Link para este artículo: http://dx.doi.org/10.14198/ALEUA.2018.29-30.04

Puede citar este artículo como:

GonZÁlez GosálBEZ, Rafael, «La experiencia teatral universitaria de nuestros cómicos en sus testimonios»,

Anales de Literatura Española, n. ${ }^{\circ}$ 29-30 (2018), pp. 97-118.

\title{
LA EXPERIENCIA TEATRAL UNIVERSITARIA DE NUESTROS CÓMICOS EN SUS TESTIMONIOS
}

\author{
RAFAEL GONZÁLEZ GOSÁLBEZ \\ Universidad de Alicante \\ orcid.org/0000-0001-8373-5552
}

\section{Resumen}

El Teatro Español Universitario (TEU) y otras iniciativas similares fueron el espacio donde muchos de nuestros actores y actrices iniciaron o consolidaron su vocación artística después de la Guerra Civil. En este artículo se repasan las experiencias en ese contexto de José Luis López Vázquez, Agustín González, Fernando Guillén, Alfredo Landa y Pilar Bardem.

Palabras clave: teatro español, teatro español universitario, TEU, actores españoles, actrices españolas, José Luis López Vázquez, Agustín González, Fernando Guillén, Alfredo Landa, Pilar Bardem.

\section{Abstract}

The Spanish University Theater (TEU) and other similar initiatives were the space where many of our actors and actresses initiated or consolidated their artistic vocation after the Civil War. The purpose of this study is to review the experiences in that context of José Luis López Vázquez, Agustín González, Fernando Guillén, Alfredo Landa and Pilar Bardem.

Keywords: Spanish theatre, teatro español universitario, TEU, Spanish actors, Spanish actress, José Luis López Vázquez, Agustín González, Fernando Guillén, Alfredo Landa, Pilar Bardem. 


\section{Introducción}

Durante décadas, la institución familiar se convirtió en una de las principales canteras con que nutrir a la profesión actoral española. En una crónica sobre la entrega del Oscar al mejor actor de reparto de 2008 a Javier Bardem -uno de los afectados por ese fenómeno-, Juan Ignacio García Garzón lo explicaba, un tanto gongorinamente, de este modo: «Como los tallos trepadores de la hiedra conjurados frondosamente sobre el muro, en el teatro español las genealogías se ramifican y entrecruzan adensándose en un tejido que soporta las claves de una profesión antigua, a veces brillante y siempre sacrificada» (ABC, 26-II-2008). En efecto, es larga la nómina de apellidos que a lo largo de la historia de nuestra interpretación se repiten en distintas épocas, a través de las generaciones, muchas veces entrecruzándose con los de otros cómicos con quienes acaban uniéndose para siempre en la memoria colectiva: Asquerino, Bardem, Dicenta, Diosdado, Merlo, Ozores, Rabal, Rivelles, Vico....

Pero, sin tener vinculación familiar alguna con el ambiente artístico y sin haber pasado de entusiastas espectadores cinematográficos, y en menor medida teatrales, en su infancia y juventud, también encontramos entre nuestros cómicos y cómicas un importante grupo cuyo desembarco en la profesión se produjo merced a una intensa voluntad, y en muchas ocasiones a pesar de la negativa reacción de sus familias. Fueron los actores, como definió César Oliva a Fernando Guillén, «de vocación más pura» (Oliva y García de Dueñas, 1999: 37). En varios de esos casos esa dedicación se consolidó, o al menos alcanzó instantes relevantes para su devenir profesional, en el marco del teatro universitario; así les sucedió a Maruchi Fresno, Manuel Alexandre, Fernando Fernán-Gómez, José María Rodero, Valeriano Andrés, Ana Mariscal, María Dolores Pradera, José María Prada, María Jesús Valdés, Juanjo Menéndez, Elvira Quintillá, la radiofónica Matilde Conesa, Jesús Puente, Carmen Bernardos, Nuria Torray, Gemma Cuervo, María Fernanda d'Ocón, Julián Mateos, Juan Diego (Román, 1996a, 1996b y 1996c; y Gómez García, 2006: 40)..., o los que protagonizan este artículo: José Luis López Vázquez (1922-2009), Agustín González (1930-2005), Fernando Guillén (1932-2013), Alfredo Landa (19332013) y Pilar Bardem (1939).

\section{Dos consideraciones previas}

Antes de adentrarnos en el tema principal de este trabajo, debemos realizar dos consideraciones estrechamente relacionadas. La primera se refiere a la caracterización cronológica del grupo de actores al que nos estamos refiriendo; la segunda es terminológica. 
Los intérpretes en cuyas experiencias nos basamos forman parte de un extenso catálogo de actrices y actores españoles que iniciaron sus trayectorias profesionales o las consolidaron a partir de la postguerra, y en concreto en las décadas de los cuarenta y cincuenta. Muchos de ellos utilizaron, para referirse a ellos mismos o a sus compañeros de profesión, los términos cómico y cómica como sinónimos de actor y actriz. Hay sobradas muestras en la bibliografía testimonial que nos ha servido de base para escribir este texto. Los actores y las actrices aquí evocados prefirieron por lo común esa denominación aun a sabiendas de que, como indicó Juan A. Ríos Carratalá, soportaba un «significado peyorativo o despectivo» (2001: 14), pues «Hablar de cómicos durante el franquismo era hacerlo de un grupo no sólo cohesionado por una práctica profesional, sino también por una mentalidad y unas costumbres que resultaban singulares en una sociedad donde todavía se observan los signos de una secular marginación» (Ríos Carratalá, 2013: 145). Fernando Fernán-Gómez, tantas veces brillante en sus apreciaciones, concretó muy bien la situación: «Los actores siempre han sido un país dentro del otro país en que estaban» (en La silla de Fernando, película-conversación dirigida por Luis Alegre y David Trueba, 2006). ${ }^{1}$ Actualmente, el empleo de cómico y cómica como sinónimos de actor y actriz es prácticamente nulo, salvo por algún veterano de la profesión, que lamentablemente escasean. Es cierto que habituales de las tablas, los platós y hasta los estudios radiofónicos e Internet, especialistas en divertir y provocar la risa con monólogos, programas televisivos y de radio (como Andreu Buenafuente, Berto Romero, Eva Hache, David Broncano o Ignatius Farray), utilizan el término para denominar su dedicación, aunque la mayoría de estos cómicos o humoristas actuales se encuentran mucho más próximos a los de las stand-up comedies estadounidenses (como Jack Benny, Lenny Bruce,

1. Precisamente en esa circunstancia veía el hispano-argentino uno de los principales alicientes de su pertenencia al mundo de los comediantes: «Siempre se ha dado por hecho que [la profesión actoral] tenía una moral distinta, más relajada. Muchos avances que consigue la sociedad ahora, los golfos de los cómicos los teníamos ya; nosotros no hemos tenido que esperar que haya ley de divorcio o que no la haya, los homosexuales han estado perfectamente bien recibidos en esta profesión, etcétera. Esto que yo considero un avance moral es lo que, cuando yo era ya un ser pensante, me parecía lo mejor de la profesión. Me parecía que había tenido una gran suerte de estar en ella» (Aguirre, 2008: 218). Adolfo Marsillach consideraba asimismo una de las cosas buenas del oficio («no todo iba a ser malo») que se rigiera «por unas normas peculiares no coincidentes con las de la sociedad civil» (1998: 521); y también María Luisa Merlo celebraba ese alejamiento del orden establecido, gracias al cual los cómicos podían vivir con franqueza el emparejamiento de dos actores aunque estuviesen casados con otras personas o incluso siendo del mismo sexo. Según la actriz valenciana, «El teatro era muchísimo más natural que la sociedad. La sociedad no era nada natural. La sociedad era francamente horrible» (Víllora, 2003: 58). 
Richard Pryor o George Carlin) que a los descendientes de nuestros cómicos de la legua.

Como hemos adelantado, la bibliografía básica para la escritura de este artículo se centra en los documentos testimoniales protagonizados por varios de estos actores y actrices, cómicos y cómicas, que se hicieron imprescindibles para el desarrollo de nuestro teatro, nuestro cine y nuestra televisión a partir de la postguerra. Es cierto que la normalización y posterior desarrollo de la literatura testimonial entre nuestros comediantes tardó en fraguar, pues no se hicieron efectivos hasta la década de los noventa del pasado siglo, inaugurada con la primera edición de uno de los títulos que, sin duda, supondrían un espaldarazo para la publicación del testimonio actoral: El tiempo amarillo, de Fernando Fernán-Gómez (1990). A partir de entonces aumentó considerablemente la edición de obras en distintos formatos (autobiografías, memorias, entrevistas de mayor o menor extensión, biografías con participación de los protagonistas, documentos audiovisuales...) que presentaban el testimonio de los intérpretes del siglo xx; la tendencia ha continuado en lo que va de centuria: en algo más de década y media de este siglo XXI se han publicado casi tantos títulos como en todo el anterior, por lo que cada vez resulta más fácil aproximarse a la memoria de nuestros cómicos para conocer de primera mano distintas cuestiones relacionadas con el desempeño de su oficio.

\section{Nuestros cómicos en la universidad y el TEU}

Uno de esos posibles temas de análisis es el referido a la formación académica de estos actores y actrices. Sus testimonios nos indican que, salvo excepciones, la condición social de las familias en las que nacieron tendía a la escasez, por lo que se hacía inevitable la rápida aportación de cualquier miembro en edad de trabajar, por temprana que fuera, alejándose así de las aulas. En los linajes de intérpretes se alternaban las épocas de desahogo económico con otras de verdadera necesidad; además, dado el ambiente en que se desarrollaban sus infancias, estos solían encaminar pronto sus pasos profesionales hacia el oficio de artista y descartar, por tanto, otras posibilidades laborales más o menos precisadas de un buen desempeño en el terreno de los estudios. Aun así, los hubo que llegaron a pisar la universidad, pero sus recuerdos nos confirman que con poco o ningún convencimiento, y por supuesto -salvo alguna honrosa excepción (Rafaela Aparicio y Antonio Ferrandis, Magisterio; Adolfo Marsillach, Derecho; José María Prada, Medicina...)- nulos resultados; no obstante, como ha quedado dicho, varios de ellos consolidaron su vocación interpretativa gracias a la extraordinaria actividad que, tras el fin de la guerra, 
extendió por los campus del país el Teatro Español Universitario, el TEU, y otras iniciativas similares.

Agustín González fue uno de esos actores cuyo paso por el sistema de educación superior se malogró antes de tiempo. Según le explicó a Lola Millás, contaba con varios antecedentes interpretativos por línea materna, que ostentaba los apellidos Calderón de la Barca; de hecho, él aseguraba descender directamente del dramaturgo del XVII (Millás, 2001: 56). Tanto su abuela como un hermano de esta eran grandes aficionados al teatro, y una de sus tías maternas, Antonia Martínez Calderón de la Barca, hermana de su madre, llegó a trabajar en la compañía de Margarita Xirgu; para su boda con el también actor José Jordá tuvo unos padrinos ilustres, nada menos que la propia Xirgu y el escritor y director teatral Cipriano Rivas Cherif. Otro hermano de su madre fue, según González, «un galán muy apreciado en los años cuarenta en España. Después se marchó a Venezuela y estuvo trabajando allí prácticamente el resto de su vida...» (57). Nuestro actor encontraba en estos antecedentes cierta responsabilidad sobre su futura dedicación; y volvería a rememorarlos al recordar sus primeras recitaciones, con diez o doce años, en el colegio: «ahí es donde también se pueden encontrar los orígenes de los genes que me habían traspasado en la familia...» (Millás, 2005: 32).

El protagonista de El caso Almería (Pedro Costa, 1984) comenzó a subirse a las tablas con diecisiete años junto a un grupo de aficionados formado en la empresa constructora donde trabajaba su padre. Precisamente sus primeros intentos de progresar en el ámbito universitario tuvieron como fin, ya hemos anticipado que no cumplido, hacer realidad el sueño de su progenitor de que estudiara Arquitectura: lo impidieron las dificultades económicas que soportaba la familia en los años cuarenta. Para no defraudarlo, el futuro actor se matricularía en las escuelas de Aparejadores y de Peritos Industriales, estudios que no le cautivaron y a los que acabaría renunciando para inclinarse por los de Filosofía y Letras. ${ }^{2}$ Sin embargo, su asistencia a clase fue escasa, pues su entrega principal se dirigió a la práctica escénica en el paraninfo de la facultad:

Más que estudiar, lo que me empezó a atraer era hacer teatro con los grupos que había en la universidad. Era mucho más excitante y esa posibilidad me abrió una ventana al mundo. Frente al aburrimiento de la rutina académica, tuve la oportunidad de hacer mi propia carrera escapando, tal vez instintivamente, por otros caminos que no eran los convencionales (Millás, 2005: 165).

2. También fue esa la carrera que quiso estudiar Adolfo Marsillach, pero se vio obligado a renunciar ante la opinión que le merecía a su padre: «Te morirás de hambre. Además, esa es una carrera femenina» (Marsillach, 1998: 88). 
Las primeras experiencias de Agustín González en el teatro universitario tuvieron lugar con la compañía La Diabla, formada por él mismo junto a, entre otros, Joaquín Pamplona y los hermanos Rafael y Emiliano Redondo. En el Parque Móvil de los Ministerios, este grupo representó «algo de [José María] Pemán y también una obra titulada Llama un inspector [de J.B. Priestley]. No sólo éramos los actores, sino que dirigíamos las obras y nos hacíamos la crítica» (Millás, 2005: 36). Ya en el TEU de la Escuela Superior de Comercio y posteriormente en el TEU de Madrid, participó en distintos montajes interpretando y dirigiendo (como expuso Juan Luis Urgel en el seminario sobre los orígenes y el desarrollo del TEU de Madrid que se celebró en la Universidad Complutense entre los días 30 y 31 de mayo de 2017). Pero sin duda las intervenciones más importantes de Agustín González en el teatro universitario se relacionan con dos estrenos celebrados en 1952 y 1953: los de Tres sombreros de copa, de Miguel Mihura, y Escuadra hacia la muerte, de Alfonso Sastre.

Ambos montajes corrieron a cargo del Teatro Popular Universitario (TPU), fundado por Sebastián Salazar. El dramaturgo Alfonso Sastre describió al TPU como «la expresión de un momento en el que todo lo que se ha hecho resulta insuficiente. Hay que salir no sólo a la calle de la ciudad -desde los limitados y asépticos recintos universitarios-, sino al campo de España. Al menos en sus comienzos, el TPU pretende ser la versión española de la inquietud que ha hecho posible el florecimiento de los teatros populares en toda Europa: de la inquietud cuya versión francesa es el TNP (Théâtre National Populaire), de Jean Vilar» (1956: 175). ${ }^{3}$

Escrita en 1932, el estreno de Tres sombreros de copa a cargo del TPU tuvo lugar veinte años más tarde, la noche del 24 de noviembre de 1952. Vale la pena recordar el contundente juicio de Francisco Ruiz Ramón sobre esa injusta demora:

Que Tres sombreros de copa no se representara a poco de haber sido escrita es un hecho lamentable que retrasó el nacimiento oficial y eficaz de un nuevo teatro de humor, y muestra patentemente el provincianismo mental y estético de los responsables -actores, directores y empresarios- de tal retraso, los cuales, como siempre, se escudaron en la falta de preparación del público, poniéndose de manifiesto, una vez más, su servidumbre a lo consagrado y al éxito comercial, su total ausencia de inquietud artística y su inhibición a

3. Pilar Suelto de Sáenz coincidía con la opinión de Sastre; para ella, la escenificación de Tres sombreros de copa marcó un cambio de fase en el ámbito del teatro universitario, pasando de una primera etapa «con actividades predominantemente dentro de la universidad» a otra «con un mayor radio de acción en los escenarios de fuera del recinto universitario» (1964: 554). En palabras de César Oliva, el Teatro Popular Universitario «sobrepasa la idea de un simple teatro universitario. Es algo más» (Oliva y García de Dueñas, 1999: 37). 
cuanto significara novedad, originalidad y renovación. En lugar de arriesgarse a ensayar lo nuevo y a renovar el gusto del público actuando creadoramente, se abstuvieron, situando así los escenarios españoles al margen de las nuevas corrientes dramáticas. Mihura, como antes Valle-Inclán, fue víctima de esa mentalidad de tenderos y de comerciantes al por menor, o al por mayor, que administraron el gusto público y los escenarios y compañías teatrales (1997: 322). ${ }^{4}$

La dirección de aquel primer montaje de Tres sombreros de copa corrió a cargo de Gustavo Pérez Puig, quien trabajó con un reparto en el que, además de Agustín González (como Don Sacramento), figuraban entre otros Juanjo Menéndez (Dionisio), José María Prada (Don Rosario) y Fernando Guillén (El Anciano Militar). ${ }^{5}$ Se trataba de una función única celebrada en lunes, día de descanso de la compañía titular del Teatro Español; el espectáculo cosechó tal triunfo que volvió a representarse al lunes siguiente, con similar fortuna, por lo que Luis Prendes decidió incluirla en el repertorio de su compañía para presentarla en el Teatro Beatriz apenas semanas después, el 19 de diciembre. Agustín González, junto a José María Prada, fue uno de los intérpretes originales de Tres sombreros... que se sumaron al proyecto de Prendes, con lo que,

4. Gonzalo Torrente Ballester opinaba que, de haberse estrenado Tres sombreros de copa en 1932, «todo el mundo sabría que el humor moderno lo habríamos inventado aquí» (1968: 448). En palabras de José Monleón, el estreno de la pieza de Mihura «constituyó un verdadero cañonazo. Quizá sea, históricamente hablando, y en su momento, con Historia de una escalera, de Buero, y Escuadra hacia la muerte, de Sastre, una de las tres piezas más importantes del teatro español propuestas a lo largo de los últimos treinta años» (1971: 88); parecer en el que coincidía Jorge Rodríguez Padrón, para quien la comedia de Mihura era «una de las obras integrantes de la trilogía fundamental en nuestro teatro de posguerra (aunque se escribiese cuatro años antes del comienzo de la contienda civil)» junto a las mencionadas de Buero y Sastre (Mihura, 1997: 23). Francisco Umbral recordaba al dramaturgo, en La noche que llegué al Café Gijón, cuando, en los años sesenta, «había abandonado ya su teatro de vanguardia y hacía unas comedias burguesas muy bien hechas, siempre irónicas con todo y consteladas por el toque vivo y eficaz de su sentido del absurdo. Me dijo que quería representar Tres sombreros de copa quitándole todas las audacias escénicas y dejándolo en una comedia de tresillo. Esto me dio mucha pena por la comedia, y me reveló que Mihura estaba evolucionando hacia los gustos de su público, cuando su público debiera haber evolucionado hacia él. Miguel Mihura tiene un escepticismo seco y sincero, nada sofisticado, sin frases, que quizá le habría llevado naturalmente a desconfiar de los alardes y audacias de otro tiempo, no por aburguesamiento, sino por simple aburrimiento» (1978: 92-93).

5. Completaban el reparto Gloria Delgado, Margarita Mas, Blanca Sendino, Conchita H. Vaquero, Lolita Dolz, Pilar Calabuig, Javier Domínguez, Juan Manuel, Antonio Jiménez, Francisco García, Agustín de Quinto y Rafael Martín Peña (CDT). Según Pérez Puig, Mihura valoró positivamente la labor de los actores: «... la interpretación de todos, desde Juanjo Menéndez a José María Prada, de Agustín González a Gloria Delgado, de Fernando Guillén a José Cerro, es estupenda» (El Cultural, 21-VII-2005). 
recordaba González, «tuve, por primera vez, un contrato sellado y rubricado por el Sindicato Vertical -que era el único que había entonces-, y a partir de ese momento me dieron carné como actor, enmarcado dentro de la normativa del Sindicato» (Millás, 2005: 37). También este segundo montaje del texto de Mihura obtuvo gran éxito, y en su décima representación se ofreció una función especial en la que colaboraron como figurantes la periodista Josefina Carabias, el cineasta Edgard Neville, el director teatral Luis Escobar, la vedette Virginia de Matos o los actores y actrices Fernando Fernán-Gómez, María Asquerino, Emma Penella y los hermanos Ozores, entre otros (CDT).

La puesta en escena de la pieza de Miguel Mihura supuso el inicio de la trayectoria profesional de Agustín González. Su representación resultó, en sus palabras, «muy significativa no sólo por lo que a mí se refiere, pues marcó un camino clarísimo de por dónde iba yo a seguir transitando, sino también porque fue el despegue de toda una generación a la que pertenezco y supuso la apertura de un espacio por donde entró aire fresco en un ambiente que tenía sus cotas más altas en teatros como el María Guerrero» (Millás, 2005: 45).

Uno de los compañeros de reparto de Agustín González en aquellas funciones de Tres sombreros de copa fue Fernando Guillén, que compaginaba estudios en la Facultad de Derecho y en el Conservatorio de Música y Declamación. Asimismo, intentó ingresar, sin suerte, en el Instituto de Investigación y Experiencias Cinematográficas para satisfacer su, en palabras de Jesús García de Dueñas, "primera y decidida vocación" (Oliva y García de Dueñas, 1999: 73), la de director de cine. Su vinculación al teatro universitario se produjo por mediación de Antonio Prieto, profesor de Literatura y director del grupo de la Facultad de Filosofía y Letras, ${ }^{6}$ quien le ofreció la oportunidad de interpretar a Don Alonso en su montaje de El caballero de Olmedo, donde coincidiría por primera vez con Agustín González, que encarnaba al criado Tello. La comedia de Lope se estrenó en el nuevo Paraninfo de la Facultad, en la Ciudad Universitaria.

6. Nacido en Águilas (Murcia), en 1929, Prieto cursó estudios de Medicina, Filología Románica y Filología Italiana en la Universidad Complutense de Madrid, institución en la que posteriormente y hasta su jubilación fue catedrático de Literatura española. Como novelista, ha obtenido el Premio Planeta por Tres pisadas de hombre en 1955, el Premio Ondas por Elegía por una esperanza en 1961, el Premio Novelas y Cuentos por Secretum en 1971, el Premio Andalucía de Novela por La plaza de la memoria en 1995 y el Premio Andalucía de la Crítica en dos ocasiones, por Isla blanca en 1998 y por Una y todas las guerras en 2004. Como ensayista ha publicado, entre otros, Los caminos actuales de la crítica (1969), Ensayo semiológico de sistemas literarios (1972), Morfología de la novela (1975) y Coherencia y relevancia textual (de Berceo a Baroja) (1980). 
También Guillén hizo una valoración muy positiva de su experiencia en Tres sombreros de copa, de la que aseguró que «fue recibida de manera entusiasta. Ni el propio Mihura se esperaba un éxito como aquel. Por eso, Gustavo [Pérez Puig] tuvo el acierto de seguir en esa línea, con obras [de las] que él supo predecir su éxito -en eso siempre ha sido muy sagaz- y con actores jóvenes de seguro porvenir. Tampoco en eso se equivocó» (Oliva y García de Dueñas, 1999: 20).

Cuatro meses después del histórico estreno de Tres sombreros de copa, el TPU puso en escena Escuadra hacia la muerte, de Alfonso Sastre, de nuevo con Agustín González, Juanjo Menéndez y Fernando Guillén en el reparto, e incorporando a otros actores, entre los que destacaba Adolfo Marsillach.

La obra de Sastre fue estrenada, también con dirección de Gustavo Pérez Puig, el 18 de marzo de 1953 en el Teatro María Guerrero. Agustín González la describió como parte de «un teatro distinto del que se venía exhibiendo comercialmente en Madrid, como Las Chirucas [sic], de Isabel Garcés, y frente a las comedias que hacían Fernando Granados y Tina Gascó, por ejemplo» (Millás, 2005: 29). ${ }^{7}$ Como explicó Eduardo Haro Tecglen, «Debió aquel estreno ser una

7. Con Las Chirucas, Agustín González se refería a la pieza de Adolfo Torrado titulada Chiruca, estrenada en 1941 con Isabel Garcés como protagonista. Fue uno de los mayores éxitos del autor coruñés, que se llevó a la gran pantalla en Argentina, en 1945, con guion de Arturo Cerretani, dirección de Benito Perojo y Elisa Christian Galvé y Catalina Bárcena en los principales papeles. Eduardo Pérez-Rasilla situó a Torrado, junto con José Echegaray y Alfonso Paso, en el grupo de los dramaturgos españoles que «en su momento alcanzaron éxitos resonantes, pero que, con el transcurso del tiempo, han caído en el más completo olvido [...] lo fueron todo en su época y [...] pasados unos años, dejaron de interesar por completo a los espectadores» (García Ruiz y Torres Nebrera, 2003: 297). Pérez-Rasilla recordaba: «Su éxito de público es indiscutible. Muchas de sus comedias llegan a ser centenarias, e incluso, como sucede con Chiruca, rondan la espectacular cifra de las mil funciones» (297). Sus piezas fueron interpretadas por algunas de las compañías más ilustres del momento: Teatro Infanta Isabel (encabezada por la citada Isabel Garcés), Gascó-Granados, María Fernanda Ladrón de Guevara, Guadalupe Muñoz Sampedro, Carmen Díaz, Carmen Carbonell-Antonio Vico, Irene López Heredia, Aurora Redondo y Valeriano León, López Somoza, Enrique Guitart... (298). Si bien la crítica de su tiempo dividió su opinión sobre Torrado, «los historiadores de la literatura dramática de la época omiten el nombre del comediógrafo y los que lo incluyen coinciden en señalar sus defectos y se congratulan del olvido al que su obra ha sido relegada, aunque admiten el éxito del que gozó en su tiempo» (298-299). César Oliva reconocía su «extraordinario éxito popular durante los [años] cuarenta» (1989: 107), que lo convirtió en «el dramaturgo más representativo del momento, fenómeno de tan alto alcance taquillero que lo hace sospechoso» (107). En su opinión, sus textos teatrales «responden a un inicial teatro para menores, no ya de edad, sino de inteligencia» (71). Según Casimiro Torreiro, «su comicidad de grueso calibre, unida a menudo a un fuerte tinte melodramático y a la explotación de lugares comunes sobre los gallegos, le hizo uno de los autores más representados del teatro español» (Borau, 1998: 858). A pesar de su temprano fallecimiento, estrenó cerca 
función única», pero «hubo de prolongarse y, finalmente, hubo de morir por presiones políticas contrarias a la obra» (1958: 17) ${ }^{8}$ A todos los intérpretes comenzaron a llegarles contratos profesionales, pero Guillén, según César Oliva, no quiso abandonar «el proceso de formación que suponían los TEUS del momento» (Oliva y García de Dueñas, 1999: 20), y participó seguidamente en El momento de su vida, de William Saroyan, con dirección de Juan García Atienza, y El jugador, de Ugo Betti, con dirección de Fernando Cobos.

En sus memorias, Adolfo Marsillach, que había estudiado la carrera de Derecho entre 1945 y 1951, describió la experiencia con la obra de Sastre como «un impresionante éxito de todos: de Alfonso [Sastre], de Gustavo [Pérez Puig], de Leo Anchoriz -fenomenal escenógrafo, actor y persona, inesperadamente desaparecido-, de Juanjo Menéndez, de Agustín González, de Fernando Guillén, de Félix Navarro, de Miguel Ángel Gil de Avalle... y mío [...]. Se dio una segunda representación y... punto: el general Moscardó cortó de raíz la futura carrera de Escuadra hacia la muerte» (1998: 163). ${ }^{9}$ El propio Alfonso

de ochenta obras teatrales, escribió libretos de zarzuela y fue guionista de películas como ¡Polizón a bordo! (Florián Rey, 1941), Bambú (José Luis Sáinz de Heredia, 1945), Botón de ancla (Miguel Lluch, 1960) o Jalisco canta en Sevilla (Fernando de Fuentes, 1948).

8. El propio Gustavo Pérez Puig recordó que al estreno siguieron dos funciones más «con el mismo éxito y, cuando íbamos a iniciar una temporada unos días después en el mismo Teatro, la denuncia de un alma caritativa diciendo que era una obra antimilitarista hizo que la censura nos la prohibiera y, con la prohibición, dejara nuestras ilusiones de continuidad al borde del camino. Pero, en el fondo, lo que nadie pudo impedir es que aquella noche del mes de febrero [sic; evidentemente se trata de un lapsus] de 1953 se consagrara en España un nuevo y gran autor: Alfonso Sastre» (1992: 23). De hecho, el crítico de ABC Antonio Rodríguez de León escribió en su crítica: «Estamos por asegurar que Alfonso Sastre acaba de ingresar, tranquila y arriscadamente, en la nómina de los autores españoles de hoy» (19-III-1953).

9. Ya en su biografía de Adolfo Marsillach, publicada en 1972, Gonzalo Pérez de Olaguer señalaba que, según el actor, las representaciones adicionales de Escuadra hacia la muerte se habían prohibido porque «Moscardó se enfadó mucho», y añadía siguiendo el relato de Marsillach: «Un día, en mi escena, se armó el gran escándalo. Mi personaje confesaba, en un momento en que estaba de guardia, que tenía miedo. Entonces hubo gente que empezó a gritar: "¡Pues yo he hecho la guerra y no he tenido miedo!". Y la obra quedó fuera de circulación...» (26). Recordemos que el general José Moscardó alcanzó celebridad durante la Guerra Civil por su defensa del Alcázar de Toledo frente al asedio de las fuerzas republicanas, lo que le supuso el título de I conde del Alcázar de Toledo. Tras la guerra, ocupó diversos cargos: Jefe de la Casa Militar del Jefe del Estado, Jefe de las Milicias de Falange Española Tradicionalista y de las Juntas de Ofensiva Nacional Sindicalista (FET y de las JONS) y capitán general de la II y IV regiones militares. Tras su retiro del Ejército al llegar a la edad reglamentaria, fue nombrado Delegado nacional de Deportes, puesto que ocupó entre marzo de 1951 y abril de 1956. Asimismo, fue el presidente del Comité Olímpico Español desde 1941. En contra del recuerdo de Marsillach, Agustín González responsabilizaba a Agustín Muñoz Grandes, ministro del Ejército, de la prohibición de una nueva función de la obra (Millás, 2005: 30). 
Sastre consideró el montaje de su texto como «un prodigio de precisión y de ajuste. El trabajo de Pérez Puig [...] acreditó el talento y la eficacia de un gran director» (1956: 175-176).

Otro de los grandes nombres de nuestra interpretación que lo intentó con la carrera de Derecho fue Alfredo Landa. Nacido en Pamplona, había pisado las tablas por primera vez, con nueve o diez años, en Figueres, adonde se había trasladado la familia debido a la profesión del padre, teniente de la Guardia Civil. Aquel estreno no dejó huella significativa en él: «la vocación no se me despertó ahí. Eso fue unos años más tarde» (Landa y Ordóñez, 2008: 30). Un nuevo destino de su progenitor llevó a Landa a San Sebastián, en cuyo Teatro Principal el futuro actor recordaba haberse convertido por vez primera en espectador, acompañado por su madre: vieron Chiruca, de Adolfo Torrado, con Isabel Garcés, en la que se convirtió en «una de las tardes más felices de mi vida» (41-42).

En sus memorias, escritas por Marcos Ordóñez, Landa aseguró que el descubrimiento de su vocación de actor, «el momento más decisivo de mi vida» (45), se produciría a la edad de catorce años, en el salón de actos del local de las Juventudes de Acción Católica de San Sebastián, cuando, formando parte de un cuadro artístico de aficionados, participó con un pequeño papel en el montaje de El verdugo de Sevilla, de Pedro Muñoz Seca; interpretaba al señor Tresolls por haber vivido en Cataluña y conocer el idioma de aquella región: a pesar de la negativa inicial a representarlo, acabaría estudiándolo «como si fuera una oposición a abogado del Estado» (45). El día del estreno, al hacer su tercer mutis, se produjo el instante que marcaría su posterior existencia, y que Landa narró así:

Estaba ya en cajas cuando escuché el aplauso. Un aplauso que era distinto de los anteriores. En aquel momento yo sentí algo extraño, algo especial. Algo que iba más allá del orgullo, de la satisfacción. Algo que no había sentido nunca. Me quedé paralizado, como si me hubiera atravesado un rayo. [...] Y escuché una voz, mi voz, pero todavía más rara, porque sonaba dentro de mi cabeza, y la voz decía: «Éste es mi camino. Yo tengo que ser cómico» (45).

No obstante, intuyendo reticencias externas, mantuvo en silencio durante tres años su deseo de ser actor, y cuando por fin lo confesó a su madre, al acabar el bachillerato, el proyecto fue pésimamente recibido: «Pero ¿tú estás loco?» (47).

En 1951, apenas meses después de morir su padre, el navarro comenzó a trabajar en la empresa Firestone-Hispania y se matriculó por libre en la Facultad de Derecho de la Universidad de Madrid, ciudad donde vivía su abuela paterna y adonde el actor en ciernes comenzó a viajar para examinarse, aunque sin mucha preparación y bastante menos entusiasmo, a tenor de sus 
propias palabras: «A mí me importaba tres huevos la carrera...» (49). Con ese panorama, la conclusión de la experiencia académica solo podía tener un final: «En primero me quedé, porque no aprobé ni una» (49).

Junto a Perico Ruiz Balerdi y los hermanos Alberto, Iñaki, Manolo y Ana Aróstegui, Landa fundó en 1952 el TEU de San Sebastián. Una de las integrantes de aquel grupo sería Maite Imaz, futura esposa del actor, y también trabajó en él, sobre todo como regidor, Antxon Eceiza, que se inició posteriormente como director y guionista cinematográfico formando tándem con Elías Querejeta (A través de San Sebastián, 1960, y A través del fútbol, 1962, ambos cortometrajes documentales) y fue asimismo el responsable de varios largometrajes, entre otros Último encuentro, con el que compitió en el Festival de Cannes de 1967.

Para Alfredo Landa, el TEU fue «un gran invento del franquismo para promover la afición entre los estudiantes» (51), y a su sucursal donostiarra la definió como «un grupo atípico, por lo mucho que nos queríamos y lo compenetrados que estábamos, en escena y fuera de ella. No había luchas de egos, no había papeles grandes ni pequeños» (52). No es de extrañar, por tanto, que definiera aquel periodo de comienzos de los cincuenta como «una de las épocas más felices de mi vida», aun sin mostrar queja alguna de lo que le llegaría después, «porque mejor no me pudo ir, pero aquel tiempo fue irrepetible» (52). El resumen de la situación resultaba inequívoco: «Todo era fuera de lo normal: la energía, las ilusiones, las ganas de hacer cosas, lo que conseguíamos a fuerza de empeño...» (52). Tanta dedicación prestó Landa a esa ocupación teatral que, con la perspectiva de los años, él mismo se sorprendía en sus memorias de que no lo hubiesen despedido de Firestone-Hispania, porque, confesaba, «no pegaba un palo al agua. Cuatro albaranes, cuatro ficheros de mercancías, nada. Pasaba las horas de oficina copiando los papeles de las funciones y memorizándolas para los ensayos de la noche. No pensaba en otra cosa, no hacía otra cosa» (52).

Esos ensayos se desarrollaban diariamente, en el Instituto de Enseñanza Media Peñaflorida (donde Landa había estudiado algunos cursos de bachillerato), de siete de la tarde a diez de la noche, durante mes y medio: «Para hacer una sola representación, por puro amor al arte, que se dice» (52). El debut de la compañía se produjo en el Teatro Principal de San Sebastián el 7 de marzo de 1953 con Una noche de primavera sin sueño, de Enrique Jardiel Poncela, autor del que también representarían Los ladrones somos gente honrada, Tú y yo somos tres, Usted tiene ojos de mujer fatal y Un marido de ida y vuelta. Landa se felicitaría, muchos años después, de la elección de aquellas piezas «porque Jardiel no sólo es una de nuestras glorias nacionales, un genio, sino también 
una escuela de comedia impresionante. Es sofisticadísimo y te permite tocar todas las gamas» (53).

Durante cinco años, entre 1953 y 1958, el TEU de San Sebastián representó cuarenta obras «llenando todos los domingos, a las once y media de la mañana» (53). Alberto Aróstegui, gran lector -especialmente de la mítica colección Teatro de la editorial Escelicer-, era el principal encargado de seleccionar los textos que el grupo habría de llevar a las tablas (53). Además de las citadas de Jardiel, también pusieron en pie, entre otras, El admirable Crichton, de James Barrie; La hermosa gente, de William Saroyan; Corazón ardiente, de John Patrick; Llama un inspector, de J. B. Priestley; La heredera, de Ruth y Augustus Goetz; Ninotchka, de M. Leygen y M.G. Sauvajon; Cinco minutos antes, de Aldo de Benedetti; La otra orilla, de José López Rubio; Veinte añitos, de Edgar Neville, o María Antonieta, de Joaquín Calvo Sotelo (52-54). Landa confesaba sentirse muy orgulloso de aquellos montajes, e incluso aseguraba que, años después, ya convertido en una estrella de la cinematografía española, todavía se encontraba con gente «que no me habla de mis películas sino de los estrenos del TEU» (54).

Tras sus primeras representaciones en el Principal, el TEU de la capital guipuzcoana comenzó a actuar asimismo en el Gran Kursaal, y posteriormente en teatros comerciales de localidades próximas, como Tolosa, Legazpi, Irún, Zumárraga... (54). Gracias a éxitos como el de Todos eran mis hijos, de Arthur Miller, pudieron presentar su trabajo en el Club Helena de Barcelona (54). En 1955, el crítico del periódico Unidad, Marcos Forcada, tras asistir a una representación de Veinte añitos, de Neville, a cargo del TEU donostiarra, publicó una crítica en la que pedía que la Diputación Provincial le concediera a Alfredo Landa una beca para hacer teatro profesional (55), lo que supuso «una tremenda inyección de moral» para el joven cómico, que sin embargo no fue suficiente para cambiar el parecer de su madre, dispuesta a toda costa a impedir que su hijo hiciera realidad su sueño artístico (55). Un año después la compañía viajaba a Madrid para participar en el concurso nacional de los TEU con la comedia barroca de enredo Lorenzo me llamo, y carbonero de Toledo, de Juan de Matos Fragoso, montaje que consiguió el premio al mejor grupo, a la mejor interpretación femenina y al mejor actor, que recayó en el propio Landa (56).

Al decir de nuestro actor, el TEU de San Sebastián fue «el primer cuadro artístico que montó a [Alejandro] Casona en España» (56); en concreto, en abril de 1957. Evidentemente, se trata de una afirmación que, por incompleta, puede tomarse por falsa, ya que, con anterioridad al conflicto, ya habían subido a las tablas de nuestro país, entre otras, La sirena varada (en 1934, con un reparto 
encabezado por Margarita Xirgu y Enrique Borrás) o Nuestra Natacha (en 1935 por la compañía de Josefina Díaz de Artigas y Manuel Collado, y en 1936 por la Compañía de Comedias de María Fernanda Ladrón de Guevara). Su intención era sin duda la de asegurar que los jóvenes donostiarras fueron los primeros en hacer regresar al asturiano a los escenarios españoles tras el trágico paréntesis de la guerra. Lo cierto es que el TEU de San Sebastián pudo estrenar -en abril de 1957, como se ha dicho-Los árboles mueren de pie, y posteriormente trataron de hacer lo propio con La barca sin pescador, pero ni el delegado gubernativo lo permitió ni al comediógrafo le pareció adecuado, ya que -al menos así lo recordaba Landa- entendía que una presencia reiterada de sus obras en los escenarios de la España franquista «comprometía su posición de exiliado» (56).

A finales de 1957, el TEU de San Sebastián «empezó a dar las últimas boqueadas»:

Lo cierto es que llevábamos mucho tiempo juntos y la gente comenzaba a cansarse, a tener trabajos fijos... Estábamos en un territorio incierto: ni estudiantes ni profesionales. Un día se iba uno, al siguiente otro decía que no le venía bien ensayar... Hubo bajas y muchas reuniones y muchas preguntas. ¿Seguimos, paramos un tiempo? Se decidió, muy democráticamente, disolver la banda con La otra orilla, de López Rubio. Fue nuestro último espectáculo. [...] Luego se creó un nuevo TEU, dirigido por Aitor de Goiricelaya, pero apenas duró seis meses (56-57).

\section{Pilar Bardem, teatro universitario al margen del TEU}

Ese mismo año de 1957, y con el objetivo de unirse en el futuro «a las monjas misioneras» (Bardem y Encinas Bardem, 2005: 82), Pilar Bardem inició la carrera de Medicina; de hecho, si comenzó aquellos estudios fue porque tenía «el deseo real» de marcharse con la madre Teresa de Calcuta, y de fructificar su sueño, quería aportar el bagaje de una formación útil en las misiones (111). Sin embargo, abandonó las aulas en segundo curso, aunque seguiría en contacto con el ambiente universitario acompañando a su novio, estudiante de Económicas.

Como le había pasado en el colegio, también en la universidad participó Pilar Bardem en algunas experiencias teatrales con alumnos de Derecho y Filosofía que, al margen del TEU, habían montado un grupo. Según la actriz, «Eran gente bien, supongo que de derechas porque ensayábamos en unas casas maravillosas y enormes por la Castellana» (119). Apenas conocerlos, le propusieron protagonizar A Electra le sienta bien el luto, de Eugene O'Neill: «Yo sabía perfectamente que estábamos perpetrando un crimen con la obra. No sé cómo me oían a mí los demás, pero yo a ellos les oía fatal» (119). Convencida de sus pocas dotes para la interpretación, no quiso desentonar asimismo en 
el plano estético: «mala actriz pero guapa porque dado que me sentaba bien el luto me alquilé para la representación un traje negro, precioso, que Marta Santaolalla -una cantante estupenda- utilizó para La viuda alegre. Como actriz estuve horrorosa, ya digo, pero mona, monísima» (119).

Tras esa experiencia, Pilar Bardem y otros compañeros del grupo contactaron con el Teatro de Cámara y Ensayo Los Independientes, compañía también surgida en el ámbito universitario que dirigía Javier Laffleur y en la que figuraban, entre otros, Carlos Ballesteros (que procedía del TEU), Margarita Calahorra o Roberto Llamas, y cuyo decorador era León Revuelta, quien, con los años, participaría en el diseño y producción de vestuario de películas como las de Mario Camus La colmena (1982) y Los santos inocentes (1984). Según Bardem, Los Independientes «hacían honor al nombre porque no se podía, y entonces menos, hacer teatro más independiente que aquél. Allí empecé a ver una calidad en los montajes y, sobre todo, una ambición que me gustó. Javier Laffleur era un director maravilloso, imaginativo, lleno de ideas fantásticas. [...] Todo era teatro absolutamente vanguardista y hecho con los mínimos medios, dado que estos montajes sólo se representaban un día» (119). La actriz distinguía claramente el trabajo que ella había realizado con aquella compañía del que llevaba a cabo el TEU, «más oficializado y manejado por la Falange que otros grupos. ¡Claro que a ver qué no estaba manejado por la Falange en aquellos días! Los demás, nosotros por ejemplo, éramos unos loquitos que hacíamos teatro vanguardista y sobre todo inédito con más coraje que medios» (120).

Con Los Independientes, Pilar Bardem participaría en el montaje de El paraíso de los imprudentes, de Walter Béneke, estrenado en el Teatro Eslava de Madrid el 27 de enero de 1959, «con fasto y esplendor [...] porque el autor era un diplomático americano que pagó y llevó a todos sus conocidos de la high society» (120)..$^{10}$ El estreno «fue movidito. En aquellos tiempos cuando en el texto pasaba algo malo, como un adulterio o cualquier situación promiscua, la acción se situaba automáticamente en el extranjero, fuera de la católica España. Yo me convertí, por tanto, en una chica francesa, malvada, alocada y con un toque de femme fatale. Vamos, un tipo de señorita que, al parecer, no entraba en lo posible que fuera española» (120). Pero el alboroto se produjo por cuestiones políticas, más que morales:

10. Completaron el reparto Ana Farra, Carlos Ballesteros, Manuel Gil y Marcelo ArroitaJaúregui. Carlos Walter Teodoro Béneke Medina era salvadoreño, nacido en 1928. Licenciado en Ciencias políticas, económicas y sociales, estudió Periodismo en Francia y en España, y Cooperativismo en Brasil. Desempeñó cargos diplomáticos en Japón, Alemania, Austria y España. Fue ministro de Educación y de Relaciones Exteriores de su país. Murió asesinado en 1980 (Diario Co Latino, 1-XI-2014). 
Todo discurría en una especie de buhardilla y en aquel decorado había, joh, sorpresa!, una bandera comunista. Se alzó el telón y lo siguiente es [sic] que alguien llamó a la policía y en cinco minutos llegaron los grises. Gran discusión, que eso no podía ser, que la representación quedaba inmediatamente suspendida... Entre el diplomático y Javier [Laffleur] consiguieron convencerles de que nos dejaran terminar el primer acto, que si el teatro estaba lleno, la gente sentada y aquello iba a ser un escándalo, que si había importantes invitados, damas de la aristocracia... Javier les aseguró que nada más caer el telón tras el primer acto quitaría la bandera, que era una banderita muy pequeña y que por supuesto no aparecería más. Lo que no les explicó es que según el propio texto la banderita desaparecería al final del primer acto. Ahí estuvo muy listo, les coló la bandera y respetó la integridad del texto (120-121).

Entre aristócratas, diplomáticos y otros personajes de la alta sociedad, aquella representación contó con un espectador verdaderamente de excepción, el actor Fernando Rey, quien, al coincidir posteriormente con Juan Antonio Bardem en el rodaje de Sonatas (1959), le transmitió una opinión muy favorable sobre las cualidades interpretativas de su hermana (121).

A pesar de la buena experiencia, Pilar Bardem acabaría por abandonar pronto esa incipiente trayectoria, ya que por entonces no se planteaba ser actriz; tenía otros planes, concretamente los de «casarme y cumplir mi sueño de tener hijos» (120).

\section{El caso 'José Luis López Vázquez'}

Tanto los actores como la actriz cuyos testimonios acabamos de rememorar constituyen un grupo de intérpretes que se vincularon al teatro universitario desde su condición de estudiantes, por poca fortuna que en ese ámbito lograran. José Luis López Vázquez, sin embargo, conforma un caso distinto, puesto que también se vinculó al TEU en sus inicios interpretativos, pero sin pasar por el trámite de la matriculación académica.

Al igual que otras figuras destacadas de la actuación en esos años, como el propio Fernando Guillén, Lola Herrera, Julia Gutiérrez Caba, Concha Velasco o María Luisa Merlo, López Vázquez fue un buen ejemplo de lo que Marcos Ordóñez denominó intérprete «autoconquistado» (2011: 91), es decir, aquel cuya primera vocación no fue la de actriz o actor. Antes de dedicarse definitivamente al oficio, el madrileño no solo realizó otras labores artísticas relacionadas con el teatro y el cine (figurinista ${ }^{11}$, decorador o ayudante de dirección), sino

11. Como recordaban Rosana Torres y Elsa Fernández Santos tras el fallecimiento del actor, en el Museo Nacional de Teatro (Almagro) se pueden ver figurines y dibujos de López Vázquez, así como otros objetos relacionados con su trayectoria profesional. El cómico donó a esa entidad, en 2007, todo el material relativo a su carrera que conservaba 
que llegó a convencerse de que, dada su falta de «palmito» al estilo de Alfredo Mayo, José Suárez o Jorge Mistral, tenía más posibilidades llevando a cabo esos trabajos que como actor (Rodríguez Merchán, 1989: 24; Lorente, 2010: 42).

Los inicios de José Luis López Vázquez en escena se sitúan en los primeros meses de la postguerra, en 1939. Nuestro actor tiene diecisiete años y, como indica Rodríguez Merchán, «Ha perdido su trabajo en el caos de la caída de Madrid y, aunque luego lo recuperará, en ese momento se encuentra sin oficio ni beneficio en una ciudad repleta de falangistas...» (1989: 18). A cambio de un pase para los comedores del Auxilio Social, se integra en la Delegación Nacional de Prensa y Propaganda, que controlaba los medios de comunicación en manos de la Falange. La labor del joven López Vázquez en aquel organismo consistía en mecanografiar notas, comunicaciones y consignas para enviar a los periódicos (Lorente, 2010: 31-32). Su presencia en tal ámbito le posibilitó el acceso a las actividades culturales que allí se desarrollaban, especialmente las del Teatro Nacional de las Organizaciones Juveniles, compañía creada en septiembre de 1939 y dirigida por Modesto Higueras, al que acompañaba el pintor José Caballero, ambos (Higueras y Caballero) antiguos integrantes de compañía La Barraca, creada a finales de 1931 con el patrocinio del gobierno de la II República y dirigida por Federico García Lorca y Eduardo Ugarte. ${ }^{12}$

en sus archivos privados (El País, 2-XI-2009). La página web del museo informa de que su colección de obra sobre papel, integrada por figurines, escenografías, dibujos y estampas, es una de las más ricas del establecimiento almagreño con más de doce mil fondos catalogados. La colección alberga bocetos, apuntes y teatrines que pertenecieron a algunos de los grandes escenógrafos y figurinistas de los últimos cincuenta años, entre los cuales se cita a Federico García Lorca, Salvador Dalí, Francisco Nieva, Carlos Cytrynowski, Miguel Narros, Gerardo Vera, Andrea D'Odorico, Sigfrido Burman y José Luis López Vázquez (Museo Nacional del Teatro). En marzo de 2013 la Fundación AISGE inauguró la exposición José Luis López Vázquez, arte en papel, que recopilaba sesenta y cinco muestras del trabajo gráfico del actor, entre figurines, escenografías, carteles de ferias, felicitaciones navideñas, etcétera. En el seminario internacional El Teatro Español Universitario (TEU) de Madrid: orígenes y desarrollo (Universidad Complutense de Madrid, 30-31 de mayo de 2017), Rebeca Bustos Sánchez dedicó su ponencia a la labor de López Vázquez como escenógrafo y figurinista del TEU.

12. Sobre la creación del Teatro Nacional de las Organizaciones Juveniles, Modesto Higueras explicó: «Durante muchos días realicé pruebas de aptitud entre chicos y chicas para formar un cuadro mixto, que era lo lógico, ya que tuve que enfrentarme a los prejuicios de los inmovilistas de siempre, con mando, claro está, y que veían en esa labor una promiscuidad peligrosa e intentaron hacer un teatro sólo de muchachos para realizar consignas o, peor, una nueva galería salesiana; vamos, una castración del autor y la consiguiente desorientación de los muchachos. Logré reunir un conjunto de veinticinco actrices y actores después de muchas pruebas, y con entusiasmo por parte de todos se llegó a un resultado más que aceptable en el debut, a finales de octubre» (Gómez García, 2006: 35).

Anales, 29-30 (2018), pp. 97-118 
La primera vez que José Luis López Vázquez pisó un escenario para actuar ante el público fue de la mano de Higueras, que dirigía el montaje de un recital titulado Pliego de romances españoles, con textos ordenados por Luis Rosales y Luis Felipe Vivanco. Ante la imposibilidad de completar el elenco, López Vázquez se ofreció para recitar los versos del poema «Albayaldos». El espectáculo se estrenó, con la presencia del Jefe de Estado, el general Franco (Gómez García, 2006: 35), a finales de octubre de 1939, en el Teatro Bellas Artes de Madrid. Tras esa experiencia, nuestro actor decidió incorporarse completa y definitivamente en la compañía de Higueras, de quien llegaría a convertirse en ayudante de dirección, sin descuidar las facetas de intérprete y figurinista.

En enero de 1941, José Miguel Guitarte, jefe nacional del Sindicato Español Universitario (SEU), encarga a Modesto Higueras la creación de un teatro universitario a semejanza, según recordaba el propio Higueras, «del que fundó tu maestro García Lorca» (Gómez García, 2006: 43), y López Vázquez no duda en acompañar al director en su nueva empresa, donde permaneció hasta 1948 con magníficas sensaciones, como recordaría en 2002:

La vida allí era maravillosa, era una tertulia continua, teníamos todos una gran afición. Modesto era un hombre muy preparado y llevábamos a escena tanto obras extranjeras como clásicos españoles. El TEU aportó todo a mi carrera. Modesto nos enseñaba dicción, recitábamos, leíamos a los clásicos... (Campus, suplemento de El Mundo, 23-V-2002). ${ }^{13}$

En 1942, para inaugurar el curso dramático del TEU, Higueras escoge El burlador de Sevilla y convidado de piedra, de Tirso de Molina, donde López Vázquez ejercía de figurinista e intérprete, en esta última faceta junto a, entre otros, Valeriano Andrés y María Jesús Valdés. El estreno en el Teatro Español fue, en palabras del director del montaje, «un gran éxito que yo ofrecí a mi maestro García Lorca, que había marcado el camino de renovación teatral y en mí la vocación de director realizador» (Gómez García, 2002: 45).

López Vázquez continuó en el TEU varios años ejerciendo de actor, aunque seguía viéndose más futuro como dibujante y figurinista, de hecho

13. En ese mismo suplemento y en esa misma fecha, María Jesús Valdés valoraba también muy positivamente su experiencia: «Los antiguos teatros universitarios hicieron muchísimo por la escena. La forma de hacer, actuar y la mentalidad moderna de Modesto Higueras fueron una gran aportación. Cuando yo entré, sobre el año 1945, el TEU ya estaba constituido. Estábamos todos en la universidad o a punto de entrar en ella. Con ese primer TEU representamos de todo, incluso estrenábamos a autores muy nuevos. Allí nos juntábamos gente de todo tipo de ideologías, pero no importaba, habíamos sufrido demasiado en aquella posguerra y ante la idea de hacer teatro todo se borraba. A través del TEU pude entrar de una manera profesional en el teatro. ¡Fíjate todo lo que me aportó el TEU!» (El Mundo, 23-V-2002). 
diseñó decorados y vestuarios tanto para montajes de la compañía de Modesto Higueras como para los de otros grupos, y trabajó para Actos Públicos, sección de la Subsecretaría de Educación Popular, diseñando gallardetes, casetas y tribunas para distintas ferias. Aún más: a su regreso de Hollywood, el dramaturgo, guionista y director de cine José López Rubio lo integró como decorador y diseñador de vestuario para sus películas Sucedió en Damasco (1943) y Eugenia de Montijo (1944); y repitió la experiencia con Pío Ballesteros (Consultaré a Mr. Brown, 1946) y Enrique Herreros (María Fernanda, la Jerezana, 1947). Sin embargo, en cuanto se le presentó la primera gran oportunidad para decantarse irreversiblemente por la interpretación no le cupo ninguna duda; se trataba de la compañía del Teatro María Guerrero, bajo la dirección de Luis Escobar, que preparaba la adaptación teatral de El anticuario, de Charles Dickens (1948). López Vázquez reconocía en ese momento el inicio de su principal trayectoria: «ahí empezó mi bagaje» (Lorente, 2010: 46).

El madrileño, creador de tantos personajes inolvidables, como el Fernando Galindo de Atraco a las tres (José María Forqué, 1962) o la Adela Castro de Mi querida señorita (Jaime de Armiñán, 1971), mostró siempre que tuvo oportunidad su agradecimiento tanto a Modesto Higueras como a José Caballero por abrirle el camino de lo que, con el tiempo, se convertiría no ya en su modo de ganarse la vida, sino en su modo de vida. Así lo hizo en 2002, en el «homenaje a toda una vida» que la Mostra de València brindó a José Luis López Vázquez (Lorente, 2010: 32-33 y versión mecanografiada por el propio actor en 387); y también en los discursos de recepción del Premio Nacional de Teatro 2003 (33 y 390) y del Goya de Honor 2004 (391). Finalmente, en octubre de 2006 participó en un homenaje a la memoria de Higueras celebrado en el Teatro Español; allí leyó su texto «A mi maestro y amigo Modesto Higueras» (33-34 y 393), donde afirmaba:

Por lo que a mí respecta, he de reconocer modestamente que el prestigio o fama -con perdón- que me adjudican, según ajena y generosa apreciación, por mi desmesurado trabajo lo debo absoluta y justamente a mi maestro Modesto Higueras, que, con paciencia y esfuerzo infinitos, logró avezarme para ejercer como mejor pude esta desconcertante pero maravillosa profesión (33).

\section{Conclusión}

Si bien la experiencia universitaria no fructificó positivamente entre nuestros actores -o cómicos- desde el punto de vista académico, sí cumplió un importante papel como espacio de iniciación o consolidación de vocaciones desde el punto de vista interpretativo. En ese terreno, el teatro universitario supuso, como señaló César Oliva, la irrupción en los escenarios de «gentes ajenas a las 
familias de actores, gentes de nueva procedencia» (Oliva y García de Dueñas, 1999: 42). Lamentablemente, no han sido muchos los actores y actrices que nos han transmitido sus testimonios sobre el tiempo transcurrido en el TEU y en otros proyectos teatrales surgidos en el ambiente universitario. Quienes nos interesamos por el recuerdo de aquellos actores y actrices como material de estudio echamos de menos los relatos autobiográficos y memorialistas de comediantes como Manuel Alexandre, José María Rodero, José María Prada, María Jesús Valdés o Juanjo Menéndez, cuyos textos en primera persona serían magníficos documentos para conocer mejor el desarrollo en nuestro país de su imprescindible oficio, y en los casos mencionados asimismo la narración de sus vivencias en el ámbito del teatro universitario. De cualquier modo, lo que resulta evidente a partir del testimonio de quienes sí nos han legado esa memoria es que para todos ellos la experiencia fue muy positiva y claramente enriquecedora, y, con la salvedad de Bardem, que se mantendría alejada de la interpretación durante años por cuestiones familiares, supuso el empuje definitivo para asentarse en la profesión actoral.

Con este trabajo, hemos intentado completar con el relato de esos cómicos lo que, desde otras perspectivas, nos ha llegado acerca del teatro español universitario. Es un paso más en nuestro deseo de incorporar la experiencia de actores y actrices al estudio del teatro y el cine realizados en España. A fin de cuentas ellos fueron, en palabras de Juan Antonio Ríos, sus «protagonistas insustituibles» (Ríos Carratalá, 2013: 161), aquellos de quienes Alfredo Hermenegildo dijo, y con razón, que constituyen «el principal agente de la práctica escénica» (Rodríguez Cuadros, 1997: 128).

\section{Bibliografía citada}

AguirRe, Arantxa, 34 actores hablan de su oficio, Madrid, Cátedra, 2008.

Alegre, Luis y David Trueba, La silla de Fernando, Plot Ediciones, 2007; DVD.

Bardem, Pilar y Carlos EnCinas BARdem, La Bardem. Mis memorias, Barcelona, Plaza \& Janés, 2005.

Borau, José Luis (dir.), Diccionario del cine español, Madrid, Alianza, 1998.

CDT (Centro de Documentación Teatral), «El histórico estreno de Tres sombreros de copa»; <http://teatro.es/efemerides/el-historicoestreno-de-201ctres-sombreros-de-copa201d> [consulta: 16 octubre 2017].

FERNÁN-GÓMEZ, Fernando, El tiempo amarillo. Memorias ampliadas (1921-1997), Madrid, Debate, 1998.

GarCía Ruiz, Víctor y Gregorio TORRes Nebrera, Historia y antología del teatro español de posguerra. Vol.1: 1940-1945, Madrid, Fundamentos, 2003. 
Gómez García, Manuel, Un hombre de teatro. Modesto Higueras. El maestro y la asamblea, Madrid, 2006.

Haro TeCGLEN, Eduardo, «Introducción a Alfonso Sastre», Primer Acto, 6 (1958), pp. 17-19.

LANDA, Alfredo y Marcos OrdóÑEz, Alfredo el Grande. Vida de un cómico. Landa lo cuenta todo, Madrid, Aguilar, 2008.

LORENTE, Luis, ¿Para qué te cuento? Biografía autorizada de José Luis López Vázquez, Madrid, Foca, 2010.

Marsillach, Alfredo, Tan lejos, tan cerca. Mi vida, Barcelona, Tusquets, 1998.

Minura, Miguel, Tres sombreros de copa, Madrid, Cátedra, 1997.

MiLlás, Lola, ¡Con Agustín González hemos topado!, Peñíscola, AISGE y XIII Festival Internacional de Cinèma de Comedia, 2001.

-, Agustín González. Entre la conversación y la memoria, Madrid, Ocho y Medio, 2005.

Monleón, José, Treinta años de teatro de la derecha, Barcelona, Tusquets, 1971.

Museo Nacional del Teatro, «Obra sobre papel»; <http://museoteatro.mcu.es/obrasobre-papel/> [consulta: 16 octubre 2017].

Oliva, César, El teatro desde 1936, Madrid, Alhambra, 1989.

Oliva, César y Jesús García Dueñas, Fernando Guillén, un actor de hoy, Murcia, Servicio de Publicaciones de la Universidad y Primavera Cinematográfica de Lorca, 1999.

ORdóñEZ, Marcos, Telón de fondo. Algunas cosas que aprendí en el teatro, Barcelona, El Aleph, 2011.

Pérez de Olaguer, Gonzalo, Adolfo Marsillach, Madrid, Dopesa, 1972.

PÉREZ Puig, Gustavo, «Alfonso Sastre. Escuadra hacia la muerte», Primer Acto, 242 (1992), pp. 22-23.

Rodríguez Merchán, Eduardo, José Luis López Vázquez. Los disfraces de la melancolía, Valladolid, Semana Internacional de Cine, 1989.

Ríos Carratalá, Juan A., Cómicos ante el espejo. Los actores españoles y la autobiografía, Alicante, UA, 2001.

-, Cómicos ante el espejo. Los actores españoles y sus memorias durante el franquismo, Alicante, Universidad (2. ${ }^{a}$ edición revisada y aumentada de Cómicos ante el espejo. Los actores españoles y la autobiografía), 2013.

RodríGuez CuAdros, Evangelina (coord.), Del oficio al mito: el actor en sus documentos, vol. I, Valencia, UV, 1997.

RomÁn, Manuel, Los cómicos. Vida y anécdota de los actores españoles más populares. Volumen V. Fernando Rey y Francisco Rabal. José María Rodero y otros grandes, Barcelona, Royal Books, 1996a.

- Los cómicos. Vida y anécdota de los actores españoles más populares. Volumen VI. Pioneros de la televisión. Vampiresas y estrellas de los 60, Barcelona, Royal Books, 1996b. 
-, Los cómicos. Vida y anécdota de los actores españoles más populares. Volumen VII. Nuria Espert y otras actrices de primera. Marisol y los nuevos valores, Barcelona, Royal Books, 1996c.

Ruiz RAmón, Francisco [1970], Historia del Teatro Español. Siglo XX, Madrid, Cátedra, 1997.

SASTRE, Alfonso, «De los teatros universitarios en España y de la necesidad de una reorganización para la enseñanza del teatro», en Drama y sociedad, Madrid, Taurus, 1956, pp. 173-179.

Suelto DE SÁENZ, Pilar, «El teatro universitario español en los últimos treinta años», Thesaurus, tomo XIX, 3 (1964), pp. 543-557.

Torrente BAllester, Gonzalo [1957], Teatro español contemporáneo, Madrid, Guadarrama, 1968

Umbral, Francisco [1977], La noche que llegué al Café Gijón, Barcelona, Destino, 1978.

Villora, Pedro M., María Luisa Merlo. Más allá del teatro, Madrid, Temas de Hoy, 2003. 